\title{
The Role of Mechanical-Electrical Interaction in Ventricular Arrhythmia: Evidence From a Novel Animal Model for Repaired Tetralogy of Fallot
}

\author{
SHUENN-NAN CHIU, SHU-CHIEN HUANG, CHI-WEI CHANG, YIH-SHARNG CHEN, HUI-CHI CHEN, MING-TAI LIN, \\ CHUN-AN CHEN, JOU-KOU WANG, AND MEI-HWAN WU
}

\begin{abstract}
Departments of Pediatrics [S.-N.C., M.-T.L., C.-A.C., J.-K.W., M.-H.W.] and Surgery [S.-C.H., Y.-S.C.], National Taiwan University Hospital and Medical College, National Taiwan University, Taipei 100, Taiwan, Republic of China; Department of Pediatrics [C.-W.C.], En Chu Kong Hospital, Taipei 100, Taiwan, Republic of China; Genomics Research Center [H.-C.C.], Academia Sinica, Taipei 100, Taiwan, Republic of China
\end{abstract}

\begin{abstract}
Pulmonary regurgitation and prolonged QRS duration of right bundle branch (RBB) block are common in repaired tetralogy of Fallot (TOF) and increase the risk of sudden death. We sought to establish an animal model to reflect both abnormalities. Twenty-one canines: group I $(n=7)$ received a surgical right ventricular outflow tract (RVOT) transannular patch plus pulmonary valve destruction; group II $(n=5)$ received RBB ablation and sham operation; and group III $(n=9)$ received combined interventions. Serial electrophysiological data were obtained up to $1 \mathrm{y}$. Procedure mortality was $27.6 \%$. At $1 \mathrm{y}$, although severe pulmonary regurgitation was documented in most dogs in groups I (71\%) and III (100\%), progressive RVOT dilatation was noted in group III. RBB block was present in all dogs in groups II and III. However, the increments of QRS duration, QTc, JTc, and QT dispersion progression between 1 mo and 1 y were all greatest in group III. Ventricular arrhythmia events were frequent in group III (median 3.3/mo) but uncommon in groups I and II (median $1 / \mathrm{mo}$ ). We have created a novel animal model that adequately reflects both the hemodynamic and electrophysiological characteristics of repaired TOF patients and can be applied to examine the risk of ventricular arrhythmias. (Pediatr Res 70: 247-252, 2011)
\end{abstract}

$\mathrm{W}$ ith the advances in cardiac interventions, most patients with tetralogy of Fallot (TOF) can survive into adulthood. Long-term follow-up, however, has revealed that these patients are at risk of ventricular arrhythmia and sudden cardiac death (1). Patients with repaired TOF commonly have complete right bundle branch block (RBBB), detected by surface electrocardiography (EKG) with prolonged QRS duration (2). This complication is related to the patch repair of the ventricular septal defect and the right ventricular outflow tract (RVOT) incision to relieve RVOT obstruction. Risk factors for ventricular arrhythmia disclosed in previous studies include hemodynamic factors such as severe pulmonary regurgitation (PR) and increased left ventricle end-diastolic pressure and electrophysiologic factors such as prolonged QRS duration $(3,4)$. The possible mechanism includes a mechanoelectrical interaction that PR could increase right

Received January 3, 2011; accepted March 15, 2011.

Correspondence: Mei-Hwan Wu, M.D., Ph.D., National Taiwan University Children's Hospital, No. 8, Chung-Shan South Road, Taipei, Taiwan 100; e-mail: wumh@ntu.edu.tw

Supported by Grant NSC96-2628-B-002-016-MY3 from National Science Council in Taiwan ventricular loading, which further aggravates QRS prolongation (5). Thus, the depolarization and repolarization inhomogeneity and secondary QT prolongation contribute to the development of ventricular arrhythmia. However, the interaction is complex and difficult to elucidate (6).

Recently, several animal models have been proposed to simulate the hemodynamic changes in repaired TOF patients by using pulmonary valvotomy or transannular patch (7-11). Although effective in hemodynamic simulation, the importance of electrophysiological factor was seldom addressed. Thus, these models may not adequately represent the whole clinical scenario of repaired TOF. We therefore created a novel animal model in which RVOT transannular patch, PR creation, and RBBB by radiofrequency ablation would all be present to simulate repaired TOF patients. By using this novel model, we also investigated both the mechanical and electrophysiological effects and the interaction between these two factors on the generation of ventricular arrhythmia.

\section{METHODS}

Animal models. This study was approved by the Institutional Animal Study Committee of National Taiwan University, College of Medicine, and was in compliance with the National Academy of Science's "Guide for the Care and Use of Laboratory Animals." Canines younger than $1 \mathrm{y}$ and weighing 10-12 kg were used. They were divided into three groups: group I (RVOT group) received surgical RVOT transannular patch and PR creation; group II (RBBB group) received right bundle branch (RBB) ablation plus infundibulotomy; group III (RVOT plus RBBB group) received surgical RVOT transannular patch, PR creation, and RBB ablation. Infundibulotomy in group II was used as a sham operation to avoid the misinterpretation of less ventricular arrhythmia because of the lack of an RVOT surgery.

All the animals underwent midnight fasting before intervention. They were then anesthetized using i.v. Virbac (2-3 mg/kg; Zoletil, Schering-Plough, Sweden) and xylazine (0.1-0.2 mg/kg; Rompun, Bayer, German) as premedication and then i.v. propofol (dose titration, Recofol, Bayer Schering, Finland) for general anesthesia. Muscle-relaxing agents with succinylcholine (1 $\mathrm{mg} / \mathrm{kg}$; Relaxin, Taiwan) were also given during operation. Antibiotics with i.v. cefazolin (Cefa, Taiwan Biotec, Taiwan) and intramuscular gentamicin (U-Gencin, Taiwan) were given after the procedure, and then oral cefazolin was given for three more days. Heart rate and blood pressure were monitored during the procedure.

Abbreviation: EKG, electrocardiography; PR, pulmonary regurgitation; RBB, right bundle branch; RBBB, right bundle branch block; RVOT, right ventricular outflow tract; TOF, tetralogy of Fallot 
RVOT patch and PR creation. Surgical RVOT patch and PR creation (groups I and III) were performed via midline sternotomy. After exploring the heart and great vessel, a $2-3 \mathrm{~cm}$ by $4-5 \mathrm{~cm}$ elliptically shaped piece of pericardium was harvested. We made a purse string suture and punched a small hole around the RVOT. We used a hook to destruct the three pulmonary valve leaflets through the center of the purse string suture. After pulmonary valve destruction, a Bermann catheter (Arrow, PA) was then introduced through the hole to the main pulmonary artery. Angiography was performed to document the presence of severe PR. Thereafter, we used a Cobra head vascular clamp to partially occlude the RVOT from the anterior surface (Fig. $1 A)$. After making a 3- to 4-cm longitudinal incision of the entire layer of RVOT across the pulmonary valve annulus, the harvested pericardium was then sutured over with 5-0 prolene to close the incision (Fig. 1B).

Infundibulotomy. The infundibulotomy (group II) was also performed through midline sternotomy. After exploring the heart and vessels and removing the pericardium, a Cobra head vascular clamp was used to partially occlude the RVOT. Then, a 3- to 4-cm longitudinal incision of the entire RVOT muscle layer was made, but sparing the pulmonary valve annulus. We then sutured the incision line directly with a 5-0 prolene suture. After inspection for bleeding, we expanded the bilateral lung and closed the sternum and skin layer by layer. Postoperative pain control was given with intramuscular Carprofen (Rimadyl, Pfizer) and oral acetaminophen.

$\boldsymbol{R} \boldsymbol{B} \boldsymbol{B} \boldsymbol{B}$ creation. For the creation of $\mathrm{RBBB}$, we used the radiofrequency catheter ablation method. Through a 5-French sheath from the femoral vein, we introduced a 5-French MARINR catheter (Medtronic, Inc., MN) into the right ventricle and the intracardiac electrogram was recorded continuously. After accurately mapping the RBB potential, we then delivered radiofrequency energy from the Atkar Radiofrequency Ablation System (Medtronic, Inc., MN). In temperature control mode with the temperature set at $60^{\circ} \mathrm{C}$, we ablated the RBB for $1 \mathrm{~min}$ and then examined the surface EKG. The procedure was deemed successful if the axis of the QRS wave shifted to the right, and the QRS duration was prolonged for at least 1.5 times the duration before ablation. Surgical procedures, either RVOT patch (group III) or infundibulotomy (group II), were performed after RBB ablation.

Follow-up of hemodynamic and electrophysiological properties. We performed 12-lead EKG for each dog under virbac and xylazine sedation before intervention, $1 \mathrm{mo}$, and then every 2 mo for $1 \mathrm{y}$ after intervention. Surface EKG was recorded through a Digitalized EKG machine (Cardio Control NV, Netherlands). QRS duration, QTc interval, JTc interval, and QT dispersion were measured manually.

Cardiac catheterization was performed before intervention and then $6 \mathrm{mo}$ and $1 \mathrm{y}$ after the intervention. After premedication with virbac and xylazine, endotracheal intubation was performed, and propofol was given for i.v. general anesthesia. Vascular access using 5 French sheaths was obtained through transcutaneous puncture of the femoral artery and vein. We then introduced a Bermann catheter into the heart chambers, and pulmonary artery pressure, right ventricle, and right atrial pressure were recorded. Pulmonary artery and right ventricle cineangiography were performed also to evaluate PR status and RVOT size. The RVOT size was measured during end-diastolic phase as the size was maximal. The PR was judged as severe degree if free PR

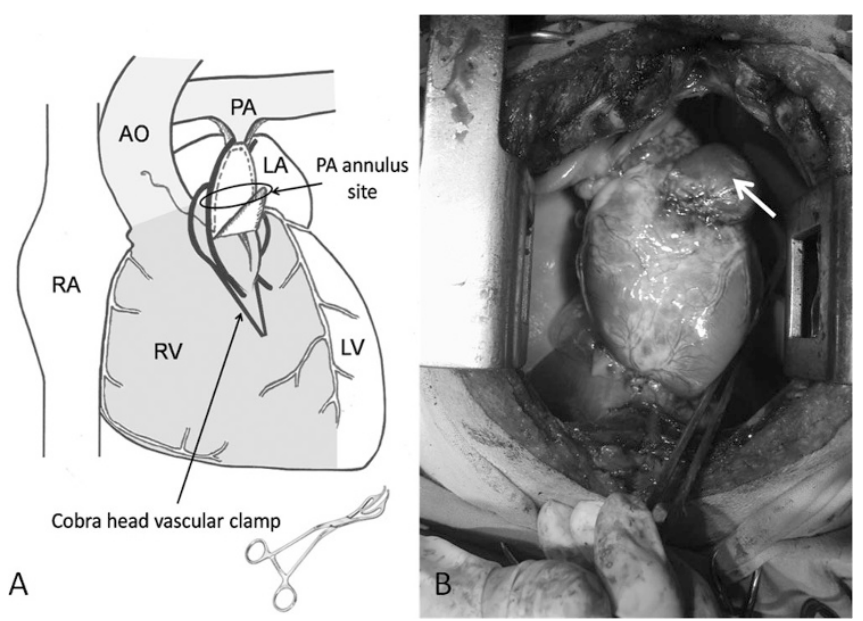

Figure 1. (A) This illustration demonstrates how we used the Cobra head vascular clamp to partially occlude the RVOT at the anterior surface and sew the pericardium on the incision line, $(B)$ the RVOT aneurysm after the procedure. LA, left atrium; LV, left ventricle; RV, right ventricle; RA, right atrium; PA, pulmonary artery; $\mathrm{AO}$, aorta. was noted and the density of contrast medium was higher in right ventricle than pulmonary artery at the first beat of pulmonary angiography. We also performed echocardiography at $1 \mathrm{y}$ after intervention. The PR severity was graded as severe if regurgitated flow was from branch pulmonary artery, moderate degree if regurgitated flow was from distal half main pulmonary artery, and mild degree if regurgitated flow was from proximal half of pulmonary artery (12). We measured the diameter of tricuspid valve and mitral valve annulus at end-diastolic phase in apical four-chamber view. The right ventricle dimension was defined as diameter of TV annulus, and the left ventricle dimension was defined as diameter of MV annulus (13).

We performed a diagnostic electrophysiology study to determine the inducibility of ventricular tachycardia. Quadrapolar electrode catheters were placed in the right atrium and the right ventricle for recording and stimulation. Through rapid right atrial pacing, wenckebach cycle length was measured. Ventricular arrhythmia inducibility was examined by right ventricle extrastimulation S1S2S3 at two sites (right ventricle apex and outflow tract) with two driven cycle lengths. The test was considered positive when more ventricular couplets were induced.

We implanted a Reveal Plus Insertable Loop Recorder (\#9526; Medtronic, Inc., MN) in randomly selected two dogs in groups I and II and three dogs in group III for continuous rhythm recording. Data retrieval was conducted directly through the programmer without sedation of the animal. Ventricular arrhythmia events were defined as ventricular triplets or short-run ventricular tachycardia.

Statistical analysis. Changes in hemodynamic and electrocardiographic parameters were presented as median and means \pm SD. Comparisons among the three groups was made by using nonparametric Kruskal-Wallis test. Wilcoxon-rank sum test was used while comparing two specific groups. The rate of ventricular arrhythmia inducibility was compared with $\chi^{2}$ test. The statistical significance was judged as a $p$ value $<0.05$ by exact method.

\section{RESULTS}

Twenty-nine dogs received the intervention and 21 of them survived the procedure. Postoperative death occurred in two dogs $(22.2 \%$, because of poor recovery from anesthesia in one and postoperative bleeding in the other) in group I, two dogs $(28.6 \%$, because of atrioventricular block after ablation in one and postoperative bleeding in the other) in group II, and four dogs $(30.8 \%$, because of poor recovery from operation in three and anesthesia related in the other) in group III. Therefore, there were seven dogs in group I, five dogs in group II, and nine dogs in group III received subsequent hemodynamic and electrophysiological evaluation.

The changes in hemodynamic and electrocardiographic parameters were summarized in Table 1 . The baseline hemodynamic and electrocardiographic parameters were similar among these three groups. At $1 \mathrm{y}$ of follow-up, the QRS duration and QTc interval all progressively prolonged in three groups but were significantly longer in those receiving RBBB ablation (groups II and III). Nevertheless, the QRS duration increment (compared with the EKG 1 mo after intervention) was greatest in group III $(15.7 \pm 5.2 \mathrm{~ms})$, lower in group II $(7.8 \pm 5.9 \mathrm{~ms})$, and lowest in group I $(5.4 \pm 9.1 \mathrm{~ms}$, group III versus I, $p=0.023$, group III versus II, $p=0.029$ ). The JTc interval and QT dispersion increment were also greater in group III than in groups I and II (Table 1).

Severe PR was noted in all dogs in group III, five of seven dogs in group I, but no more than mild degree in all dogs in group II by echocardiography data $1 \mathrm{y}$ after intervention. For hemodynamic data, the diastolic pulmonary artery pressure $1 \mathrm{y}$ after operation was lowest in group III (Table 1). The difference between diastolic pulmonary artery pressure and right ventricle end-diastolic pressure was significantly lower in group III than in group II. This implies that the PR was most severe in group III. From angiographic study, we found that 
Table 1. Electrocardiographic and hemodynamic data of the three groups of dogs

\begin{tabular}{|c|c|c|c|c|}
\hline Parameters & Group I $(\mathrm{n}=7)$ & Group II $(\mathrm{n}=5)$ & Group III $(\mathrm{n}=9)$ & $\begin{array}{l}p \text { (group I } v s \text { II, I } v s \\
\text { III, II } v s \text { III) }\end{array}$ \\
\hline \multicolumn{5}{|l|}{ EKG data at baseline and $1 \mathrm{y}$} \\
\hline QRS duration $(\mathrm{ms})$ baseline & $50(54.7 \pm 10.9)$ & $63(60.2 \pm 5.9)$ & $53(56.3 \pm 8.8)$ & 0.439 \\
\hline QTc interval $\left(\mathrm{ms}^{1 / 2}\right)$ baseline & $313(311.3 \pm 21.9)$ & $312(315 \pm 14.3)$ & $310(306.6 \pm 24.4)$ & 0.795 \\
\hline JTc interval $\left(\mathrm{ms}^{1 / 2}\right)$ baseline & $244(237.9 \pm 25.8)$ & $225(229.6 \pm 11.6)$ & $234(231.4 \pm 21.5)$ & 0.538 \\
\hline QTd dispersion (ms) baseline & $20(19.4 \pm 5.9)$ & $20(20.0 \pm 4.0)$ & $16(16.4 \pm 3.7)$ & 0.289 \\
\hline QRS duration (ms) $1 \mathrm{y}$ & $65(65.4 \pm 7.9)$ & $100(103.2 \pm 10.1)$ & $103(103.6 \pm 5.4)$ & $0.001(0.003,<0.001,0.699)$ \\
\hline QTc interval $\left(\mathrm{ms}^{1 / 2}\right) 1 \mathrm{y}$ & $315(321.0 \pm 25.5)$ & $358(351.4 \pm 21.6)$ & $356(363.2 \pm 17.7)$ & $0.011(0.03,0.003,0.518)$ \\
\hline JTc interval $\left(\mathrm{ms}^{1 / 2}\right) 1 \mathrm{y}$ & $226(226.9 \pm 21.4)$ & $212(206.4 \pm 15.7)$ & $216(222.6 \pm 13.9)$ & 0.221 \\
\hline QTd dispersion (ms) $1 \mathrm{y}$ & $28(28.0 \pm 5.7)$ & $20(24.0 \pm 4.9)$ & $32(31.1 \pm 9.3)$ & 0.117 \\
\hline \multicolumn{5}{|l|}{ EKG parameters change } \\
\hline QRS progress $(\mathrm{ms})$ & $6(5.4 \pm 9.1)$ & $6(7.8 \pm 5.9)$ & $17(15.7 \pm 5.2)$ & $0.025(0.876,0.023,0.029)$ \\
\hline QTc progress $\left(\mathrm{ms}^{1 / 2}\right)$ & $-7(-9.4 \pm 20.6)$ & $-9(-8 \pm 22.0)$ & $24(30.4 \pm 21.6)$ & $0.005(1.000,0.002,0.012)$ \\
\hline $\mathrm{JTc}$ progress $\left(\mathrm{ms}^{1 / 2}\right)$ & $-16(-16.3 \pm 20.9)$ & $-29(-19.2 \pm 23.1)$ & $21(14.2 \pm 13.5)$ & $0.007(0.876,0.003,0.019)$ \\
\hline QTd progress $(\mathrm{ms})$ & $0(0.6 \pm 10.9)$ & $-4(-7.2 \pm 13.1)$ & $8(8.9 \pm 7.4)$ & $0.034(0.268,0.091,0.019)$ \\
\hline \multicolumn{5}{|l|}{ Electrophysiological data at $1 \mathrm{y}$} \\
\hline Ventricular arrhythmia inducibility & $1(14.3 \%)$ & 0 & $1(11.1 \%)$ & 0.692 \\
\hline $\begin{array}{l}\text { Median ventricular arrhythmia events } \\
\text { recorded by loop recorders }\end{array}$ & $1 / \mathrm{mo}$ & $1 / \mathrm{mo}$ & $3.3 / \mathrm{mo}$ & 0.096 \\
\hline \multicolumn{5}{|l|}{ Hemodynamic data at baseline and $1 \mathrm{y}$} \\
\hline Systolic PA pressure baseline $(\mathrm{mm} \mathrm{Hg})$ & $19(18.5 \pm 2.5)$ & $16(17.2 \pm 3.0)$ & $20.5(20.1 \pm 2.0)$ & 0.158 \\
\hline Systolic PA pressure 1 y (mm Hg) & $24(23.7 \pm 2.9)$ & $20(22.8 \pm 5.4)$ & $23(23.2 \pm 6.7)$ & 0.925 \\
\hline Diastolic PA pressure baseline (mm Hg) & $6(6.3 \pm 2.4)$ & $5(5.6 \pm 2.0)$ & $11(9.4 \pm 3.7)$ & 0.136 \\
\hline Diastolic PA pressure 1 y $(\mathrm{mm} \mathrm{Hg})$ & $4.5(4.7 \pm 3.9)$ & $8(6.6 \pm 2.4)$ & $3(2.9 \pm 1.8)$ & 0.063 \\
\hline RVESP baseline (mm Hg) & $21(20.8 \pm 3.4)$ & $18(18.6 \pm 3.6)$ & $23.5(22.2 \pm 3.4)$ & 0.226 \\
\hline RVESP 1 y (mm Hg) & $27(28.0 \pm 7.1)$ & $25(25.8 \pm 3.3)$ & $23(24.3 \pm 7.5)$ & 0.681 \\
\hline RVEDP baseline (mm Hg) & $0(0.5 \pm 0.8)$ & $0(0.2 \pm 0.5)$ & $2.5(2.0 \pm 1.8)$ & 0.118 \\
\hline RVEDP 1 y $(\mathrm{mm} \mathrm{Hg})$ & $1(0.8 \pm 0.8)$ & $0(0.8 \pm 1.1)$ & $1(2.2 \pm 2.8)$ & 0.654 \\
\hline $\begin{array}{l}\text { Diastolic PA pressure minus RVEDP at } \\
\text { baseline }(\mathrm{mm} \mathrm{Hg})\end{array}$ & $6(5.8 \pm 2.4)$ & $5(5.4 \pm 2.1)$ & $8(7.4 \pm 2.8)$ & 0.368 \\
\hline $\begin{array}{l}\text { Diastolic PA pressure minus RVEDP at } \\
6 \mathrm{mo}(\mathrm{mm} \mathrm{Hg})\end{array}$ & $4(3.9 \pm 1.8)$ & $4.5(4.5 \pm 1.3)$ & $1(0.7 \pm 3.0)$ & $0.003(0.527,0.003,0.003)$ \\
\hline $\begin{array}{l}\text { Diastolic PA pressure minus RVEDP at } \\
1 \mathrm{y}(\mathrm{mm} \mathrm{Hg})\end{array}$ & $3(3.8 \pm 4.3)$ & $6(5.8 \pm 1.8)$ & $1(0.7 \pm 3.7)$ & $0.034(0.247,0.224,0.007)$ \\
\hline \multicolumn{5}{|l|}{ RVOT diameters data at baseline and $1 \mathrm{y}$} \\
\hline RVOT diameters baseline $(\mathrm{mm})$ & $7.46(7.41 \pm 0.81)$ & $7.44(7.21 \pm 0.50)$ & $7.60(7.96 \pm 0.83)$ & 0.193 \\
\hline RVOT diameters 1 y (mm) & $12.45(12.94 \pm 0.82)$ & $10.66(10.53 \pm 10.67)$ & $17.48(17.47 \pm 2.06)$ & $<0.001(0.004,0.001,0.001)$ \\
\hline $\begin{array}{l}\text { RVOT diameters changes between } 6 \mathrm{mo} \\
\text { and } 1 \mathrm{y}(\mathrm{mm})\end{array}$ & $1.81(1.63 \pm 0.82)$ & $1.48(1.59 \pm 0.74)$ & $2.52(3.21 \pm 2.44)$ & $0.141(0.931,0.088,0.147)$ \\
\hline
\end{tabular}

Data were presented as median (mean $\pm \mathrm{SD}$ ). The $p$ value $<0.05$ was marked in italic.

PA, pulmonary artery; RVESP, right ventricle end-systolic pressure; RVEDP, right ventricle end-diastolic pressure.

the RVOT dilation was common in groups III and I. The maximal diameters of RVOT at 1 y follow-up were greatest in group III than in groups I and II (Table 1). We also found the RVOT diameter enlarged steadily with time in groups III and I (Fig. 2). The RVOT diameter changes between 6 mo and 1 y was a little higher in group III but not statistically significant $(p=0.088$, Table 1). From the echocardiography data, we found the right ventricle (RV) dimension/left ventricle (LV) dimension was significantly larger in group III (median 1.01, $1.00 \pm 0.17$ ) than in group I (median $0.73,0.73 \pm 0.13, p=$ $0.013)$. These results suggest the additive effect of electrophysiologic factors on the mechanical factors (RVOT lesions) in $\mathrm{RV}$ dilatation.

As the electrophysiological studies, ventricular arrhythmia was induced in one of seven (14.3\%) dogs in group I, zero of five dogs in group II, and one of nine (11.1\%) dogs in group III at half year after intervention (Fig. $3 A$ ). At $1 \mathrm{y}$, ventricular arrhythmia could also be induced in one (14.3\%) of seven dogs in group I, zero $(0 \%)$ of five dogs in group II, and one $(11.1 \%)$ of nine dogs in group III. The differences were not

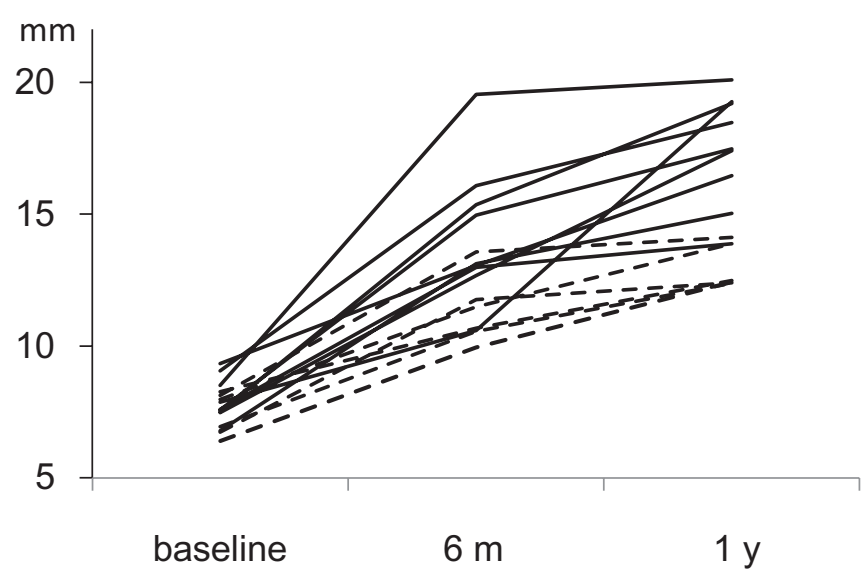

Figure 2. This figure showed the diameters of RVOT increased significantly with time in those receiving both procedures (group III, solid lines) and RVOT interventions (group I, dotted lines). The comparisons of the change between basic and 6 mo and between 6 mo and $1 \mathrm{y}$ were significantly different with $p$ value $<0.01$. 


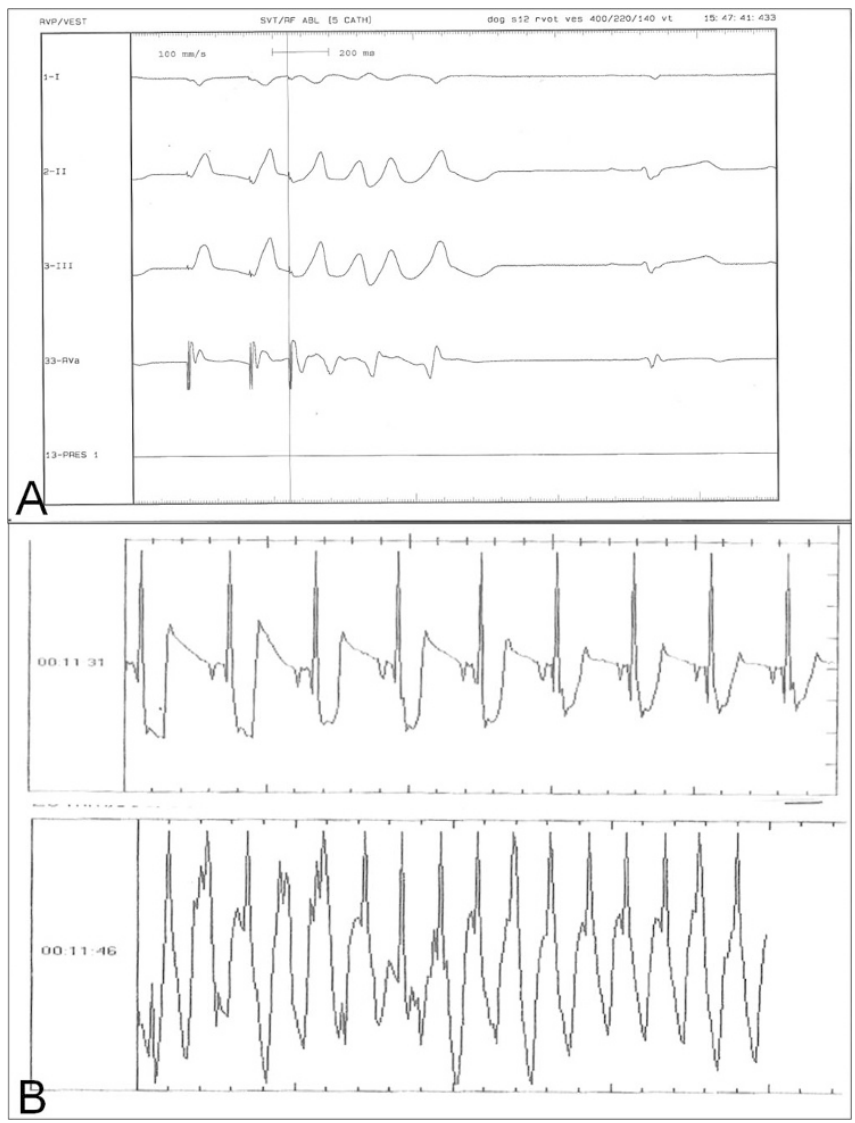

Figure 3. (A) This figure showed an example of ventricular triplet induced by RVOT ventricular extrastimulation in a dog in group III at $1 \mathrm{y}$. $(B)$ This figure showed an example of short-run ventricular tachycardia detected by event recorders in a dog in group III at 11 mo after intervention. The above is the EKG before ventricular arrhythmia.

statistically significant among these three groups $(p=0.692)$. The data of ventricular effective refractory period, wenckebach period of atrioventricular node, and atrial effective refractory period, revealed no significant differences either among the three groups or between preprocedure and $1 \mathrm{y}$ follow-up. Using loop event recorders with continuous rhythm recording, ventricular arrhythmia events could be found in all the dogs (Fig. 3B). However, ventricular arrhythmia events were most common in dogs of group III (median 3.3/mo) and occasionally in dogs of groups I and II (both median 1/mo; Fig. 4). A trend of higher frequency of events was found in group III although not statistically significant because of small case number. In addition, comparing the data between the first 3 mo and the last 3 mo using Mann-Whitney $U$ test, we found a trend of increasing ventricular arrhythmia events with time in groups III and II but not in group I ( $p=0.026,0.029$, and 0.2 , respectively).

\section{DISCUSSION}

Through surgical RVOT transannular patch and pulmonary valve destruction, and radiofrequency ablation to create RBBB, we successfully created a novel animal model that can adequately reflect the status of repaired TOF patients with similar hemodynamic and electrophysiology characteristics. Such animal models will offer the opportunity to study indi-

\section{Event no.}

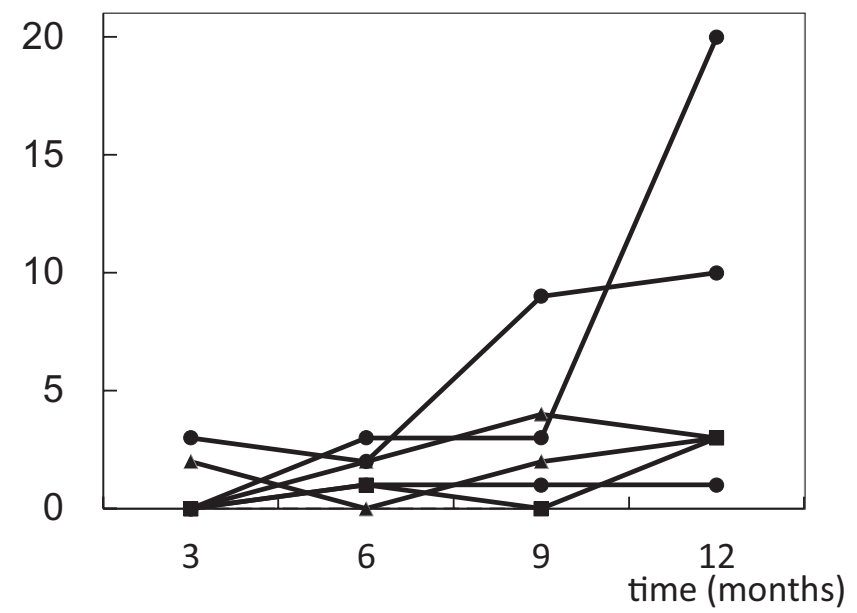

Figure 4. In this figure of ventricular arrhythmia episodes (including shortrun ventricular tachycardia and ventricular triplet) $v$ s time, we can see that the ventricular arrhythmia events increased significantly with time in group III dogs (receiving both right ventricular outlet tract reconstruction and RBB ablation). The median ventricular arrhythmia events in the last 3 mo were $3.3 /$ mo in group III and 1 mo in both groups I and II. Triangle, group I; square, group II; and circle, group III.

vidual factors and the interactions for repaired TOF patients and also provide insight for intervention refinement.

There have been several animal models proposed to simulate the pathophysiological change of repaired TOF patients (7-11). Most of these animal models involve pulmonary valvotomy or stenting of the RVOT to create PR $(7,8)$. Additional pulmonary artery banding was sometimes performed to augment the PR (10). However, although PR is an important factor relating to ventricular arrhythmia in repaired TOF patients, other mechanisms such as transannular patch, RVOT scar, and prolonged QRS duration also contribute to the development of ventricular arrhythmia. In patients with isolated PR, ventricular arrhythmia or cardiac events occur only rarely before $40 \mathrm{y}$, whereas in repaired TOF patients, the ventricular arrhythmia may occur at as early as $20 \mathrm{y}$ after operation $(14,15)$. Recently, one study had described a model using transannular patch to simulate the PR in repaired TOF (9). They incised the anterior cusp of the pulmonary valve but the subsequent PR status after operation was not described. In our initial trial, we found that the transannular patch alone could produce only a mild to moderate degree of PR. Therefore, we added the pulmonary valve destruction on the RVOT transannular patch to simulate the PR in repaired TOF. In addition, RBBB was created by radiofrequency ablation to simulate the electrophysiological changes, which are also associated with the risk of ventricular arrhythmia after TOF repair. We found that after these interventions, the RVOT size enlarged with time and the QRS duration lengthened gradually. These changes satisfactorily reflect the postoperative status of TOF patients, and demonstrate that our model is an effective animal model for studying repaired TOF.

The mechanisms of ventricular arrhythmia in repaired TOF patients include macroreentry and repolarization heterogeneity (16-18). The risk factors are 2-fold: 1) hemodynamic factors and 2) electrophysiological factors $(1,3,4,19)$. The 
hemodynamic risk factors include PR, right ventricle outflow transannular patch, increased right ventricle systolic pressure, and older age at operation. The electrophysiologic risk factors include prolonged QRS duration, increased JTc interval, QRS dispersions, and QT dispersions $(3,4,18)$. Gatzoulis et al. $(5,20,21)$ proposed that electromechanical interaction of the above risk factors [i.e. the hemodynamic factors may aggravate QRS (depolarization) prolongation and JT (repolarization) inhomogenicity] might result in ventricular arrhythmia. Although this hypothesis has been examined in several human studies (6), it has never been proven. Zeltser et al. (10) have proposed a piglet model in which PR was created by pulmonary valvotomy and pulmonary artery banding. Using the inducibility of ventricular arrhythmia 4 mo after operation as the endpoint, they found that the pulmonary valvotomy was an important predictor for arrhythmia in these piglets. This piglet model addressed the importance of isolated PR on ventricular arrhythmia, but the interaction with electrophysiological factors commonly seen in repaired TOF cannot be examined by this model.

As shown in this study, we found that the progressive changes of QRS duration and JTc interval prolongation were most profound in those receiving both $\mathrm{RBB}$ ablation and RVOT transannular patch plus pulmonary valve destruction. In addition, by using loop event recorders for ventricular arrhythmia detection, ventricular triplets or short-run ventricular tachycardia were noted more often in those receiving both interventions. These results suggest that the hemodynamic and electrophysiological factors interaction is indeed important in causing ventricular arrhythmia in repaired TOF patients. In addition, by angiographic data, we found RVOT diameters enlarged more in those receiving both RVOT interventions and RBB ablation. Through measuring tricuspid valve and mitral valve annulus by echocardiography, we found not only the RVOT but also the right ventricular inlet portion was enlarged more in those receiving both procedures. This may imply that both hemodynamic and electrophysiological factors contribute to the right ventricle dilatation. The electrophysiological factors as RBBB may cause right ventricle dyssynchrony, which compromised the right ventricular function and resulted in further dilatation of right ventricle $(22,23)$. Several previous studies had shown the important role of right ventricular dyssynchrony on the progression of right ventricular dysfunction, right ventricular dilatation, and exercise tolerance (22-25). Furthermore, tissue Doppler imaging study in this animal model will be helpful to delineate more clearly the interaction between electrophysiological and hemodynamic factors.

Study limitation. For the total correction in TOF, RVOT reconstruction and ventricular septal defect repair are both required. When considering ventricular arrhythmia in repaired TOF, RVOT lesions including transannular patch and PR and electrical factors as QRS prolongation are considered to be most important factors $(1,3,4,18,19,21)$. In the long-term follow-up data of repaired ventricular septal defect patients, we did not find significant increment of ventricular arrhythmia events and late cardiac deaths (26). This factor may hence not be an important factor in ventricular arrhythmia in repaired
TOF patients. Therefore, in our animal model, we focused only on RVOT interventions and electrophysiological interactions but not on ventricular septal defect lesions.

The follow-up duration of our animal model was relatively short compared with repaired TOF patients, which may cause less ventricular arrhythmia inducibility in our study animals. We therefore made a large transannular RVOT patch (as in Fig. $1 B$ ) to augment the effect of RVOT aneurysm. Thereby, we found that the extent of QRS duration prolongation and RVOT size enlargement approached to those in the repaired TOF patients at their adulthood (27).

In the repaired TOF patients, the cause of RBBB may be related to RVOT incision, infundibulectomy, and ventricular septal defect repair. When designing the animal model, we found that the QRS duration was still narrow despite an RVOT incision scar of up to $4 \mathrm{~cm}$. As shown in previous canine studies, RBBB could not be created by ventriculotomy alone, and right septal incision was necessary for the presence of RBBB on surface EKG $(28,29)$. Therefore, we adopted radiofrequency ablation to create $\mathrm{RBBB}$. Although the cause of RBBB is different from the cause in repaired TOF patients, the change of ventricular activation sequence and its relevant depolarization and repolarization heterogeneity after radiofrequency ablation of RBBB is similar to repaired TOF patients $(29,30)$. Because of the budget limit, we implanted loop event recorders in some but not all the dogs. This may reduce the statistical power to see the significant meaningful difference in ventricular arrhythmia.

\section{CONCLUSION}

Through RBB ablation, RVOT transannular patch, and pulmonary valve destruction, we successfully created a novel animal model that can satisfactorily reflect the hemodynamic and electrophysiological status of repaired TOF patients. In this animal model, the hemodynamic and electrophysiological factors and particularly the interactions contribute to the generation of ventricular arrhythmia. This model can be effectively applied to future studies to examine the risk of ventricular arrhythmias and potential modifiers.

\section{REFERENCES}

1. Nollert G, Fischlein T, Bouterwek S, Bohmer C, Klinner W, Reichart B 1997 Long-term survival in patients with repair of tetralogy of Fallot: 36-year follow-up of 490 survivors of the first year after surgical repair. J Am Coll Cardiol 30:13741383

2. Sarubbi B, Li W, Somerville J 2000 QRS width in right bundle branch block. Accuracy and reproducibility of manual measurement. Int J Cardiol 75:71-74

3. Khairy P, Harris L, Landzberg MJ, Viswanathan S, Barlow A, Gatzoulis MA, Fernandes SM, Beauchesne L, Therrien J, Chetaille P, Gordon E, Vonder Muhll I, Cecchin F 2008 Implantable cardioverter-defibrillators in tetralogy of Fallot. Circulation 117:363-370

4. Khairy P, Dore A, Poirier N, Marcotte F, Ibrahim R, Mongeon FP, Mercier LA 2009 Risk stratification in surgically repaired tetralogy of Fallot. Expert Rev Cardiovasc Ther 7:755-762

5. Gatzoulis MA, Till JA, Somerville J, Redington AN 1995 Mechanoelectrical interaction in tetralogy of Fallot. QRS prolongation relates to right ventricular size and predicts malignant ventricular arrhythmias and sudden death. Circulation 92:231237

6. Uebing A, Gibson DG, Babu-Narayan SV, Diller GP, Dimopoulos K, Goktekin O, Spence MS, Andersen K, Henein MY, Gatzoulis MA, Li W 2007 Right ventricular mechanics and QRS duration in patients with repaired tetralogy of Fallot: implications of infundibular disease. Circulation 116:1532-1539

7. Gray R, Greve G, Chen R, Fry C, Barron D, Lab MJ, White PA, Redington AN, Penny DJ 2003 Right ventricular myocardial responses to chronic pulmonary 
regurgitation in lambs: disturbances of activation and conduction. Pediatr Res 54:529-535

8. Kuehne T, Saeed M, Gleason K, Turner D, Teitel D, Higgins CB, Moore P 2003 Effects of pulmonary insufficiency on biventricular function in the developing heart of growing swine. Circulation 108:2007-2013

9. Yerebakan C, Klopsch C, Prietz S, Boltze J, Vollmar B, Liebold A, Steinhoff G, Sandica E 2009 Pressure-volume loops: feasible for the evaluation of right ventricular function in an experimental model of acute pulmonary regurgitation? Interact Cardiovasc Thorac Surg 9:163-168

10. Zeltser I, Gaynor JW, Petko M, Myung RJ, Birbach M, Waibel R, Ittenbach RF, Tanel RE, Vetter VL, Rhodes LA 2005 The roles of chronic pressure and volume overload states in induction of arrhythmias: an animal model of physiologic sequelae after repair of tetralogy of Fallot. J Thorac Cardiovasc Surg 130:1542-1548

11. Kaltman JR, Gillespie MJ, Seymour T, Khan A, Zeltser IJ, Rhodes LA, Tanel RE, Vetter VL, Gaynor JW, Shah MJ 2007 Substrate characterization of ventricular tachycardia in a porcine model of tetralogy of Fallot using noncontact mapping. Pacing Clin Electrophysiol 30:1316-1322

12. Goldberg SJ, Allen HD 1985 Quantitative assessment by Doppler echocardiography of pulmonary or aortic regurgitation. Am J Cardiol 56:131-135

13. Harada K, Toyono M, Yamamoto F 2004 Assessment of right ventricular function during exercise with quantitative Doppler tissue imaging in children late after repair of tetralogy of Fallot. J Am Soc Echocardiogr 17:863-869

14. Bouzas B, Kilner PJ, Gatzoulis MA 2005 Pulmonary regurgitation: not a benign lesion. Eur Heart J 26:433-439

15. Shimazaki Y, Blackstone EH, Kirklin JW 1984 The natural history of isolated congenital pulmonary valve incompetence: surgical implications. Thorac Cardiovasc Surg 32:257-259

16. Zeppenfeld K, Schalij MJ, Bartelings MM, Tedrow UB, Koplan BA, Soejima K, Stevenson WG 2007 Catheter ablation of ventricular tachycardia after repair of congenital heart disease: electroanatomic identification of the critical right ventricular isthmus. Circulation 116:2241-2252

17. Kriebel T, Saul JP, Schneider H, Sigler M, Paul T 2007 Noncontact mapping and radiofrequency catheter ablation of fast and hemodynamically unstable ventricular tachycardia after surgical repair of tetralogy of Fallot. J Am Coll Cardiol 50:21622168

18. Sarubbi B, Pacileo G, Ducceschi V, Russo MG, Iacono C, Pisacane C, Iacono A, Calabrò R 1999 Arrhythmogenic substrate in young patients with repaired tetralogy of Fallot: role of an abnormal ventricular repolarization. Int J Cardiol 72:73-82
19. Therrien J, Siu SC, Harris L, Dore A, Niwa K, Janousek J, Williams WG, Webb G, Gatzoulis MA 2001 Impact of pulmonary valve replacement on arrhythmia propensity late after repair of tetralogy of Fallot. Circulation 103:2489-2494

20. Gatzoulis MA, Till JA, Redington AN 1997 Depolarization-repolarization inhomogeneity after repair of tetralogy of fallot: the substrate for malignant ventricular tachycardia? Circulation 95:401-404

21. Gatzoulis MA, Balaji S, Webber SA, Siu SC, Hokanson JS, Poile C, Rosenthal M, Nakazawa M, Moller JH, Gillette PC, Webb GD, Redington AN 2000 Risk factors for arrhythmia and sudden cardiac death late after repair of tetralogy of Fallot: a multicentre study. Lancet 356:975-981

22. Brili S, Alexopoulos N, Latsios G, Aggeli C, Barbetseas J, Pitsavos C, Vyssoulis G, Stefanadis C 2005 Tissue Doppler imaging and brain natriuretic peptide levels in adults with repaired tetralogy of Fallot. J Am Soc Echocardiogr 18:1149-1154

23. Liang XC, Cheung EW, Wong SJ, Cheung YF 2008 Impact of right ventricular volume overload on three-dimensional global left ventricular mechanical dyssynchrony after surgical repair of tetralogy of Fallot. Am J Cardiol 102:1731-1736

24. Salehian O, Burwash IG, Chan KL, Beauchesne LM 2008 Tricuspid annular systolic velocity predicts maximal oxygen consumption during exercise in adult patients with repaired tetralogy of Fallot. J Am Soc Echocardiogr 21:342-346

25. Abd El, Rahman MY, Hui W, Yigitbasi M, Dsebissowa F, Schubert S, Hetzer R, Lange PE, Abdul-Khaliq H 2005 Detection of left ventricular asynchrony in patients with right bundle branch block after repair of tetralogy of Fallot using tissue-Doppler imaging-derived strain. J Am Coll Cardiol 45:915-921

26. Chiu SN, Wang JK, Lin MT, Chen CA, Chen HC, Chang CI, Chen YS, Chiu IS, Lue $\mathrm{HC}$, Wu MH 2007 Progression of aortic regurgitation after surgical repair of outlet-type ventricular septal defects. Am Heart J 153:336-342

27. Khairy P, Landzberg MJ, Gatzoulis MA, Lucron H, Lambert J, Marçon F, Alexander ME, Walsh EP 2004 Value of programmed ventricular stimulation after tetralogy of fallot repair: a multicenter study. Circulation 109:1994-2000

28. Moak JP, Garson A Jr 1988 Experimental right ventriculotomy: effects on local propagation at a small size scale. Pediatr Res 23:433-438

29. Sugenoya J, Sugiyama S, Wada M, Niimi N, Oguri H 1977 Body surface potential distribution following the production of right bundle branch block in dogs. Effects of breakthrough and right ventricular excitation on the body surface potentials. Circulation 55:49-54

30. Horowitz LN, Simson MB, Spear JF, Josephson ME, Moore EN, Alexander JA, Kastor JA, Edmunds LH Jr 1979 The mechanism of apparent right bundle branch block after transatrial repair of tetralogy of Fallot. Circulation 59:1241-1252 